\title{
11. COMPUTED TOMOGRAPHY SCAN IMAGE ANALYSIS OF SEDIMENTS ${ }^{1}$
}

\author{
Juichiro Ashi ${ }^{2}$
}

\begin{abstract}
Three-dimensional high-resolution images of density distributions were obtained on unsplit cores using a medical X-ray computed tomography (CT) scanner. The resolution of CT scanning is about $0.6 \mathrm{~mm}^{2}$ and allows a $5-\mathrm{mm}$ depth for beam width. Electrical resistivity measurements were also conducted to know porosity at high depth resolution after core splitting. Wholeround core samples for this study were collected from Sites 948 and 949 in the northern Barbados ridge accretionary prism during Ocean Drilling Program Leg 156. On the basis of the relationship between densities and linear attenuation coefficients of standard samples, densities derived from CT scans are consistent with densities by the mass/volume method of all the samples irrespective of their compositions. Sample disturbance is easily detected in CT-scan images by convolutional texture in CT images perpendicular to core axes. This nondestructive technique provides reliable densities at high depth resolutions for evaluating disturbances by drilling or core splitting.
\end{abstract}

\section{INTRODUCTION}

A large amount of physical property data has been collected worldwide by Deep Sea Drilling Project (DSDP) and Ocean Drilling Program (ODP) cruises. During Leg 156, a logging-while-drilling (LWD) tool acquired density and formation conductivity profiles (Shipley, Ogawa, Blum, et al., 1995). This logging technique is very effective, especially in the accretionary prism where boreholes are unstable. Moore et al. (1995) reported abnormally low density in the décollement zone, suggesting the existence of high pore-pressure zones. Continuous or dense shipboard measurements of physical properties are required for correlation with logging data and studies of high-resolution sedimentary environments. ODP shipboard measurements of sediment density are usually made on cores at intervals of several decimeters. The gamma-ray attenuation porosity evaluator (GRAPE) has provided bulk density data (Evans, 1965) at 2-cm depth intervals. Without considering core condition, however, bulk densities derived from GRAPE can be misleading or incorrect due to original and/or artificial fracturing, or gas expansion (Westbrook, Carson, Musgrave, et al., 1994; Shipley, Ogawa, Blum, et al., 1995). The X-ray computed tomography (CT) technique has the advantage of being nondestructive and providing high-resolution density data and images. Use of the CT technique for geological samples has increased recently (e.g., Vinegar, 1986; Kenter, 1989; Kimura et al., 1989; Holler and Kögler, 1990; Orsi, 1994; Orsi et al., 1994; Boespflug et al., 1995). CT studies of internal structures and density determinations were also done for deep-sea drilling samples (Soh et al.,1993; Rutledge et al., 1995; Ashi, 1995).

During Leg 156, eight whole-round and one half-round core samples were collected from the toe of the northern Barbados accretionary prism (Fig. 1, Table 1). All samples consist of semiconsolidated gray, light brownish gray, or pale yellowish claystone. In this study, $\mathrm{CT}$ and electrical resistivity are employed to evaluate small-scale density and porosity variations, respectively. Both results are calibrated using discrete physical property data.

${ }^{1}$ Shipley, T.H., Ogawa, Y., Blum, P., and Bahr, J.M. (Eds.), 1997. Proc. ODP, Sci. Results, Vol. 156: College Station, TX (Ocean Drilling Program).

${ }^{2}$ Geological Institute, University of Tokyo, 7-3-1 Bunkyo Hongo, Tokyo, 113 Japan. ashi@geol.s.u-tokyo.ac.jp

\section{METHODS}

\section{Computed Tomography Scanning}

Two types of commercial medical X-ray CT scanners (Toshiba TCT-700S and Xforce) were used to acquire the CT images. In these systems, the X-ray source produces a fan-shaped collimated beam, and the beam rotates around the sample, with a detector pad at the opposite side. The CT scan image is mathematically reconstructed using the intensities of the transmitted X-ray beam collected at regular increments of rotation around the sample (Iwai, 1979; Morgan, 1983). The intensity of the transmitted X-ray beam is usually expressed as the CT value, i.e., the ratio of the linear attenuation coefficient $\mu$ of the material to that of pure water. A two-dimensional, black-and-white image corresponding to $\mathrm{CT}$ values is derived by irradiating a slice of finite thickness. Two different procedures were adopted for each scanner. In the TCT-700S type, samples were turned on the core axes and slice images were taken at $15^{\circ}$ intervals. Blackand-white images from the CT scan were constructed using histogram equalization, which determines brightness windows and ranges, on the image processing system (Inazaki and Nakano, 1993). Histogram equalization provides contrastive images for structure observations. In the Xforce type, 2-mm slice profiles were taken sequentially from the top to the bottom of each whole-round core, and processed to make three-dimensional images by the core analysis system at Technology Research Center, Japan National Oil Corporation (JNOC). As a result, three-dimensional images derived from the Xforce scanner are helpful in the understanding of internal core structures. Reconstruction using 2-mm slices, however, results in a slight degradation of the images. CT scan data using TCT-700S are mainly discussed below.

The unit volume for which the CT value is acquired depends on the slice width of scanning. This is changeable within $1,2,5$, and 10 $\mathrm{mm}$, although the resolution in a profile image is $\sim 0.6 \mathrm{~mm}^{2}$. Using a 5-mm slice width, the unit volume corresponds to a $0.6 \mathrm{~mm} \times 0.6 \mathrm{~mm}$ $\times 5.0 \mathrm{~mm}$ cube. CT values were calibrated for density using six bentonite standards with different densities regulated by void ratio (Ashi, 1995). The linear regression is

$$
\text { density }=\mathrm{CT} \text { value } / 1250+1.0\left(\mathrm{R}^{2}=0.902\right) \text {. }
$$

Linear attenuation coefficients depend on material compositions (e.g., Hounsfield, 1973). This is a question to be considered later. 

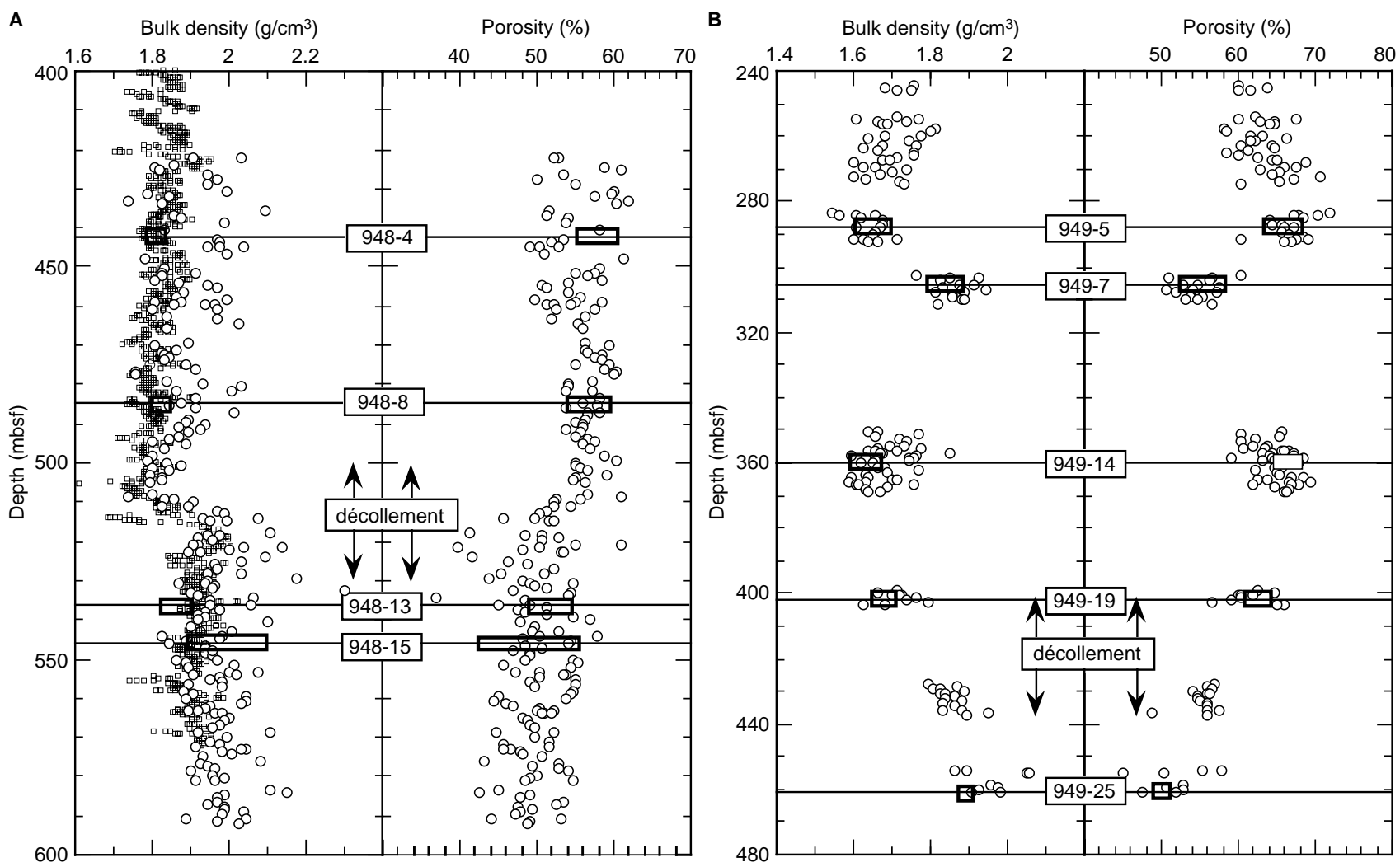

Figure 1. Bulk density and porosity vs. depth for Holes 948C (A) and 949B (B). Circles are derived from shipboard measurements of index properties (Shipley, Ogawa, Blum, et al., 1995). Bulk densities from the LWD tool in Hole 948A are also shown (open squares). Rectangles show maximum and minimum values of bulk density and porosity data measured on discrete samples from whole-round cores.

Table 1. Eight whole-round and one half-round core samples used in this study.

\begin{tabular}{lccccl}
\hline Sample ID & Hole & Core & Section & $\begin{array}{c}\text { Interval } \\
(\mathrm{cm})\end{array}$ & $\begin{array}{l}\text { Depth } \\
(\mathrm{mbsf})\end{array}$ \\
\hline $948-4$ & $948 \mathrm{C}$ & $4 \mathrm{X}$ & 2 & $20-41$ & 441.9 \\
$948-8$ & $948 \mathrm{C}$ & $8 \mathrm{X}$ & 4 & $70-80$ & 483.9 \\
$948-13$ & $948 \mathrm{C}$ & $13 \mathrm{X}$ & $\mathrm{CC}$ & $15-25$ & 536.46 \\
$948-15$ & $948 \mathrm{C}$ & $15 \mathrm{X}$ & 1 & $93-103$ & 546.33 \\
$949-5$ & $949 \mathrm{~B}$ & $5 \mathrm{X}$ & 4 & $43-56$ & 287.73 \\
$949-7$ & $949 \mathrm{~B}$ & $7 \mathrm{X}$ & 4 & $42-55$ & 307.02 \\
$949-14$ & $949 \mathrm{~B}$ & $14 \mathrm{X}$ & 4 & $33-45$ & 359.73 \\
$949-19$ & $949 \mathrm{~B}$ & $19 \mathrm{X}$ & 3 & $95-106$ & 402.25 \\
$949-25$ & $949 \mathrm{~B}$ & $25 \mathrm{H}$ & 2 & $84-93$ & 460.74 \\
\hline
\end{tabular}

Note: Sample 948-15 is a half-round core.

Figure 2 shows the density profiles estimated from CT values along a core axis line (solid circle) and $2 \mathrm{~cm}$ to the left (open circle) and right of it (triangle). Also shown are density values calculated from mass and volume measurements (dashed lines). In addition, Figure 2 shows selected CT scan images of whole-round cores (right), with photographs of split-core faces (center). Brighter parts in CT scan images, indicating higher CT values, correspond to higher densities. Brightness, however, cannot be correlated among the scans, because the windows and ranges used in this study were different in each image.

\section{Electrical Resistivity}

Electrical resistivity measurements (Boyce, 1968; Kermabon et al., 1969) can be used to estimate porosity at high depth resolutions. The probe and resistivity device used in this study were designed at the Bedford Institute of Oceanography and are the same as those used for shipboard electrical resistivity measurements (Westbrook, Carson, Musgrave, et al., 1994) and shore-based study (Ashi, 1995) of Leg 146. The probe consists of four pins, $2.5 \mathrm{~mm}$ apart. An alternating current is applied to the outer electrodes and the resistance of the sediment between the two inner electrodes is calculated from the measured voltage. Resistivity is defined as the resistance of a unit area across a unit length.

Electrical resistivity measurements were made on the split-core samples. The choice of cutting direction was selected according to the CT scan images. To evaluate anisotropy of resistivity, voltages were applied in both transverse (horizontal) and longitudinal (vertical) directions relative to the core axes, and spaced at intervals of 0.5 $\mathrm{cm}$ or $1 \mathrm{~cm}$. Longitudinal resistivities were measured sequentially along the center line of the split core and at $2 \mathrm{~cm}$ to the left and right; transverse resistivities were measured at $1 \mathrm{~cm}$ to the left and right of the center line.

Porosity can be estimated using the formation factor (Archie, 1942), which is the ratio of the resistivity of the sediment to that of the pore fluid (assumed seawater), using the following modified Archie equation (Lovell, 1985):

$$
\text { formation factor }=a \cdot \text { porosity }^{-m} \text {, }
$$

where $a$ and $m$ are constants attributed to grain size and composition. The coefficients $a$ and $m$ were determined by plotting formation factor vs. measured porosity and fitting an exponential curve to these data.

The quality of resistivity measurements is attributed in large part to the condition of the contacts between the sample and the electrical 
probes. Resistivity data are, therefore, collected from portions of core where no fracture is observed, and data from samples in which cracks formed during measurements are excluded.

\section{Sediment Index Properties}

After resistivity measurements, samples of approximately $12 \mathrm{~cm}^{3}$ were collected at $2-\mathrm{cm}$ intervals for index property measurements. Bulk density was calculated from wet mass and volume (mass/volume method) using an electronic balance and a Beckman air-comparison pycnometer under helium-displacement. Core specimens must be dried to obtain moisture content. To retain the interlayer water of clay minerals, oven temperature was set low. After drying at $50^{\circ} \mathrm{C}$ for $24 \mathrm{hr}$ and freeze drying for $24 \mathrm{hr}$, dry weight and volume were measured. The freeze-drying time is determined by no weight change during drying in various density samples. Results are plotted in Figure 1 . Such index property data from split cores provided control data for evaluating CT values and formation factors.

\section{RESULTS}

Multidirectional CT images are useful for understanding the orientations of layers or shapes of deformation structures. Figure 2A shows folded lamina and slightly inclined lamina truncated by a sharp horizontal plane in Sample 948-15. Burrows developed at the upper part are obscure because of limited CT resolution (Fig. 2A). If an object within a core is large enough for CT resolution corresponding to scan-slice width, a small density contrast, much less than 0.2 $\mathrm{g} / \mathrm{cm}^{3}$, is recognized by CT-scan method. In Sample 949-5 (Fig. 2B), a sharp density boundary with a dip of about $60^{\circ}$ is observed. This boundary is interpreted to be a healed fault because a probable shallow dip in bedding is recognized at the top of this core (Fig. 2B).

The most conspicuous structures in CT images are thin horizontal zones up to $6 \mathrm{~mm}$ thick, which display slight downward deflection at the margins (Figs. 2A, 2C, 2D, 2E). Observation of split-core faces shows that these features correspond to rotation planes formed by drilling disturbance. Deformation along these planes is evidenced by marked convolutional textures in CT scan images (Fig. 3A). The brightness of the thin horizontal zones is slightly higher or lower than surrounding materials, implying positive or negative density contrast (e.g., Figs. 2A, 2C, 2D, 2E). Where drilling disturbance extends over a whole core (drilling breccia), no obvious rotation plane is observed in split-core faces (Fig. 2F). In this case, the CT scanner can capture images similar to those observed in rotation planes (Fig. 3B). Fractures characterized by abnormally low $\mathrm{CT}$ values because of voids are also well recognized as dark parts in CT images.

Mean CT values, which are derived from sampling the same volume as that used for index property determination, are compared with bulk densities by the mass/volume method (Fig. 4). Cross plots of CT values and bulk densities are consistent with the linear relationship obtained using standard bentonite samples. Some data points with relatively large deviations are thought to be caused by sample conditions or compositions, as discussed below. Density profiles vs. depth for each core are shown in Figure 2. Densities calculated from CT values are always lower than bulk densities by the mass/volume method at the intervals where fractures are well developed. Large discrepancies are found in Sample 948-8 (Fig. 2C) and at the bottom of Sample 948-15 (Fig. 2A). In contrast, densities estimated from CT values are much lower than bulk densities from the upper half of Sample 948-13, although there is no difference from the lower half in structure, grain size, and lithology (Fig. 2D).

The CT method provides more detailed distributions of density than the conventional mass/volume method. In fact, a 2-cm sampling interval was adopted to reduce errors caused mainly by volume measurements. To evaluate short interval changes of densities calculated from CT values, electrical resistivity, which can be measured at inter- vals less than $5 \mathrm{~mm}$, is used for porosity estimation. Where the fluctuation of grain density is small, variations of porosity and bulk density should be inversely correlated. A best fit in the Archie equation between formation factors calculated from resistivities and mass/volume derived porosities gives the coefficients $a=2$ and $m=1.76$.

There are correlations between resistivity-derived porosity and mass/volume-derived porosity in Samples 948-4, 948-13, 949-7, and 949-25 (Figs. 2D, 2G, 2H). Some samples indicate discrepancies between porosities derived from resistivity and mass/volume measurements (Fig. 2). The largest discrepancy is observed in Sample 948-8, which is highly fractured (Fig. 2C). This sample also shows very low $\mathrm{CT}$ values in comparison with the mass/volume-derived densities, as mentioned above.

Anisotropy of electrical resistivity is clearly recognized in Samples 948-13, 948-15, and 949-25 (Figs. 2A, 2D, 2I). Porosity calculated from transverse (horizontal) resistivity is always approximately $7 \%$ lower than that from longitudinal (vertical) resistivity. A similar discrepancy (less than 5\%) is also observed in Sample 949-19 (Fig. 2E).

\section{DISCUSSION}

Discrepancies between porosities derived from resistivity and mass/volume measurements may be due to the inadequate coefficients $(a$ and $m$ ) for porosity estimations from formation factors. Such discrepancies, however, occur only in samples that contain many visible fractures (Figs. 2B, 2C, 2E, 2F). It is likely that microscopic cracks increase resistivity because of the high electrical conductivity of the void filled by air.

The anisotropy of resistivity has been examined to investigate the microfabric of sedimentation or tectonic deformation in deep-sea drilling samples (Tamaki, Piscicotto, Allan, et al., 1990; Ashi, 1995; Shipley, Ogawa, Blum, et al., 1995), although no anisotropy was recognized by previous work. Strong anisotropy was observed in Samples 948-13, 948-15, and 949-25 (Figs. 2A, 2D, 2I), which are characterized by weakly developed cleavage. Development of subhorizontal cleavage is thought to produce an anisotropy characterized by low horizontal and high vertical resistivities. However, results from resistivity measurements show evidence to the contrary. High horizontal resistivities are probably caused by open cracks when probes were inserted along the cleavage. The fact that porosity calculated from vertical resistivity coincides with mass/volume-derived porosity (Figs. 2A, 2D, 2I) suggests that probe alignment normal to the cleavage may instead close microcracks along the cleavage. Electrical resistivity measurements are inappropriate for sedimentary fabric analyses, which are done by anisotropy of magnetic susceptibility (Shipley, Ogawa, Blum, et al., 1995), because of disturbance by probe insertion.

In Sample 948-13, CT-derived densities at the upper half are much higher than the bulk densities by the mass/volume method (Fig. 2D). It is difficult to consider large differences in attenuation coefficients because grain sizes and grain densities are almost constant from the top to the bottom within this sample. Disturbance during core splitting is the most plausible cause.

Whether the relationship between CT value and density estimated from standard samples can be applied to sediments is discussed by Ashi (1995) and many others. The main concern is that natural sediments include grains with various attenuation coefficients. Also, the polychromatic nature of the X-ray beam results in a nonlinear response to bulk density. Comparison of mass/volume-derived densities with mean CT values, which are derived from sampling portions for index property measurements, indicates no systematic deviation (Fig. 4). This may be caused by relatively high pore-water content and negligible variations in composition and grain size.

Figure 1 shows that bulk densities by the mass/volume method in this study are close to corresponding shipboard bulk density data. 

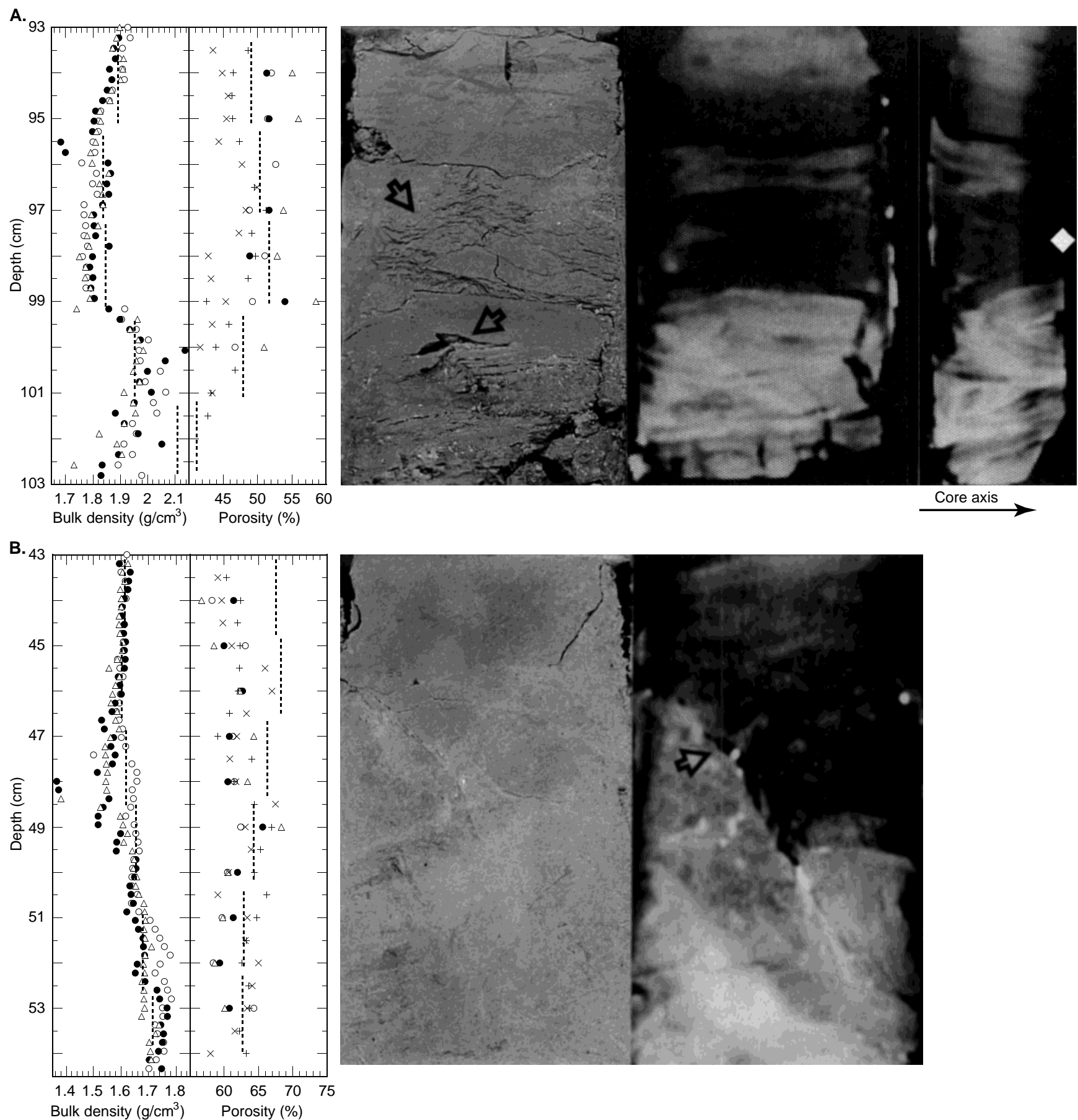

Bulk density $\left(\mathrm{g} / \mathrm{cm}^{3}\right) \quad$ Porosity $(\%)$

Figure 2. Density and porosity vs. depth (left), core photographs (center), and CT scan images (right). Three density profiles estimated by CT scans show density distributions of samples along a core axis line (solid circles), $2 \mathrm{~cm}$ left of the axis (open circles) and $2 \mathrm{~cm}$ right of the axis (triangles). Dashed line intervals represent values of core specimens measured by the mass/volume method. Porosity profiles were estimated from electrical resistivity measurements made in longitudinal (vertical) and transverse (horizontal) directions. Longitudinal measurements were made sequentially along a core axis line (solid circles) and $2 \mathrm{~cm}$ to the left (open circles) and right of it (triangles). Transverse measurements were made at $1 \mathrm{~cm}$ to the left (crosses) and right (pluses) of the core axis. Porosities calculated from mass and volume measurements are also shown (dashed lines). Brighter portions on CT scan images indicate higher density. A. Sample 948-15 (halfround). The direction of the CT image on the right is perpendicular to the split-core face. Note the cleavage (upper arrow) and the fault and drag folds (lower arrow). Diamond (right) shows the position of drilling disturbance example (see Fig. 3C). B. Sample 949-5. Note the fault showing a sharp density boundary (arrow). C. Sample 948-8. Note the rotation plane (diamond) between biscuits. The CT image is shown in Figure 3A. D. Sample 948-13. E. Sample 949-19. F. Sample 949-14. A light brownish gray claystone shows the texture of drilling breccia. The diamond shows the typical convolutional texture in CT images perpendicular to core axes (see Fig. 3B). G. Sample 948-4. H. Sample 949-7. Vertical lines at the upper part are artifacts probably caused by the sample shape. Subtle differences in CT values are enhanced by histogram equalization during image processing. I. Sample 949-25. Note the well-developed cleavage. 

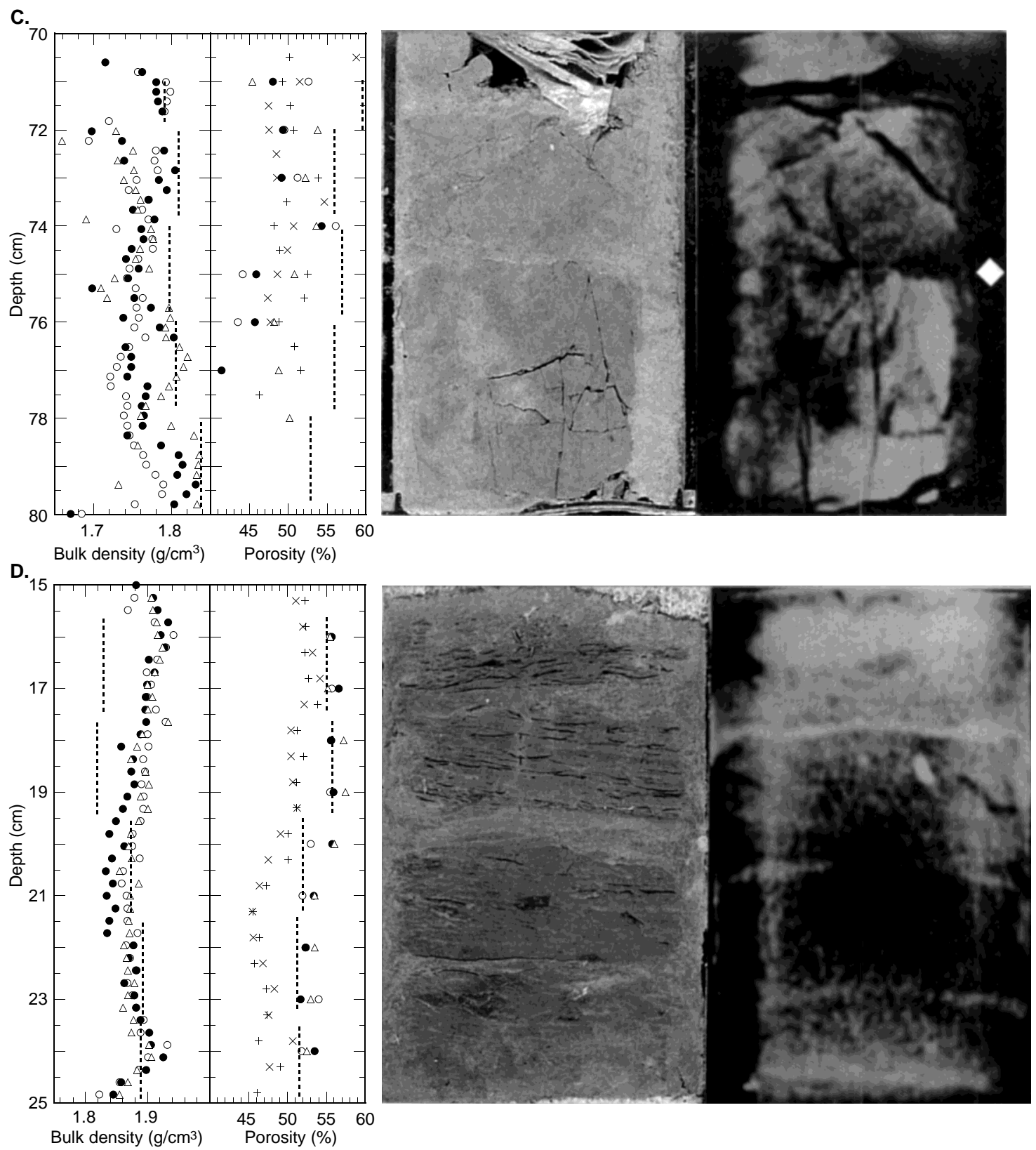

Figure 2 (continued).

Large discrepancies $\left(\sim 0.5 \mathrm{~g} / \mathrm{cm}^{3}\right)$ between Sample 948-13, and shipboard data are probably due to the derivation of this sample from the core catcher (Fig. 1A). The bulk densities from the shipboard measurements tend to be higher than densities estimated by the LWD tool and this study (Fig. 1A). During shipboard measurements of index properties, massive cubic samples were selectively taken for $P$-wave and $S$-wave velocity measurements. In contrast, the LWD tool obtained in situ densities and CT scanner measured densities of wholeround cores successively at high depth resolution. High densities from shipboard measurements are perhaps attributed to sampling from higher consolidated parts. Resistivity data from Site 948 using the LWD tool (Shipley, Ogawa, Blum, et al., 1995) provide formation factors ranging from about 6 (above the décollement) to 4 (below it). These values coincide with data from this study above the décollement (about 6) and are much lower than those from below the décollement (about 6.5). The cause of this discrepancy remains an unresolved question.
CT images are useful in the examining of three-dimensional structures and drilling disturbances. In this study, most samples are highly deformed by drilling, and no significant tectonic structure is observed (Fig. 2). In Sample 948-15, scaly fabric and a healed fault with drag folds have developed (Fig. 2A), suggesting tectonic- or gravity-induced structures. These structures are, however, associated with horizontal discontinuities caused by drilling rotations (Fig. 2A, Fig. 3C) and interpreted as drilling disturbance structures.

\section{CONCLUSIONS}

A medical X-ray CT scanner was used to acquire high-resolution images and density distributions of marine sediments from ODP Leg 156. Knowledge of the relation between density and the linear X-ray attenuation coefficient of standard samples made possible quantitative discussion of even small sample volumes. Following this rela- 
E.
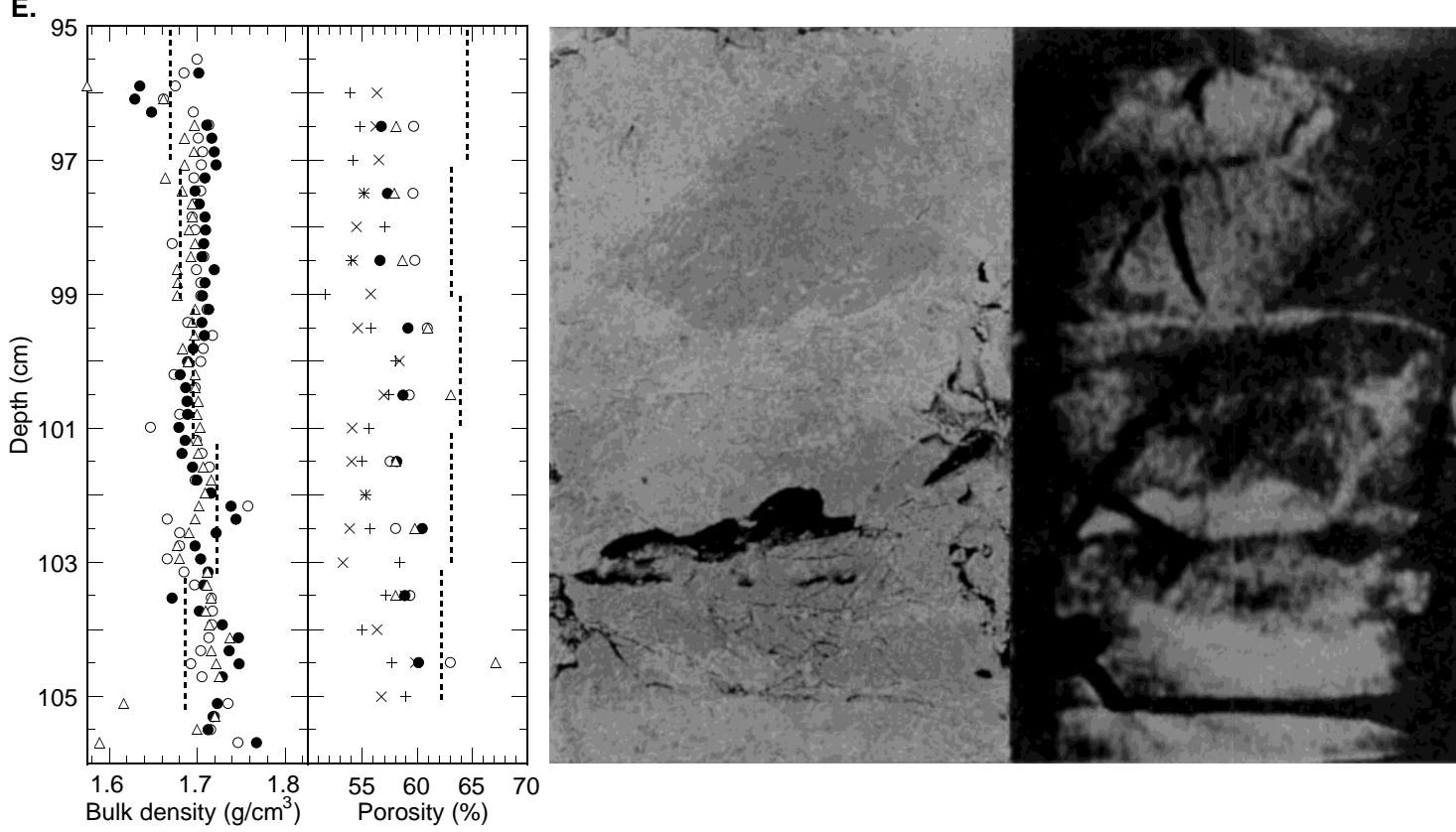

F.

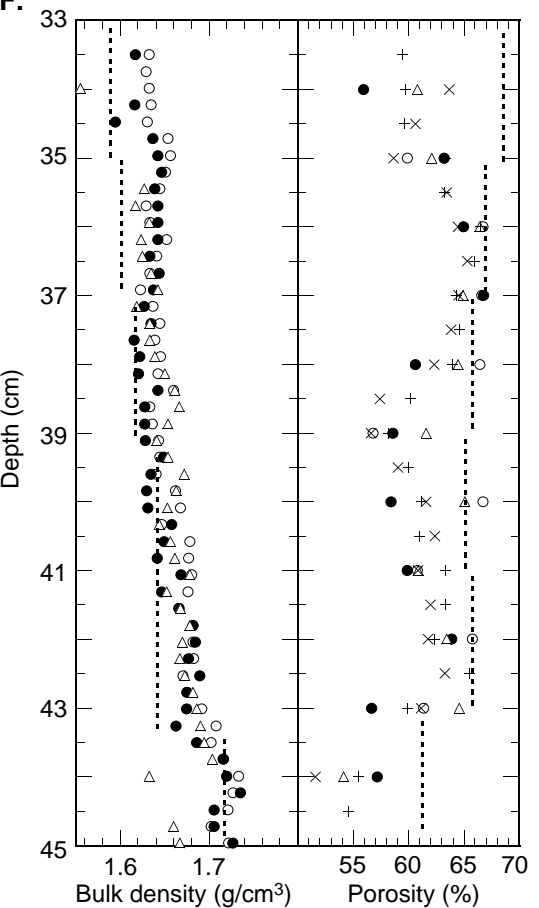

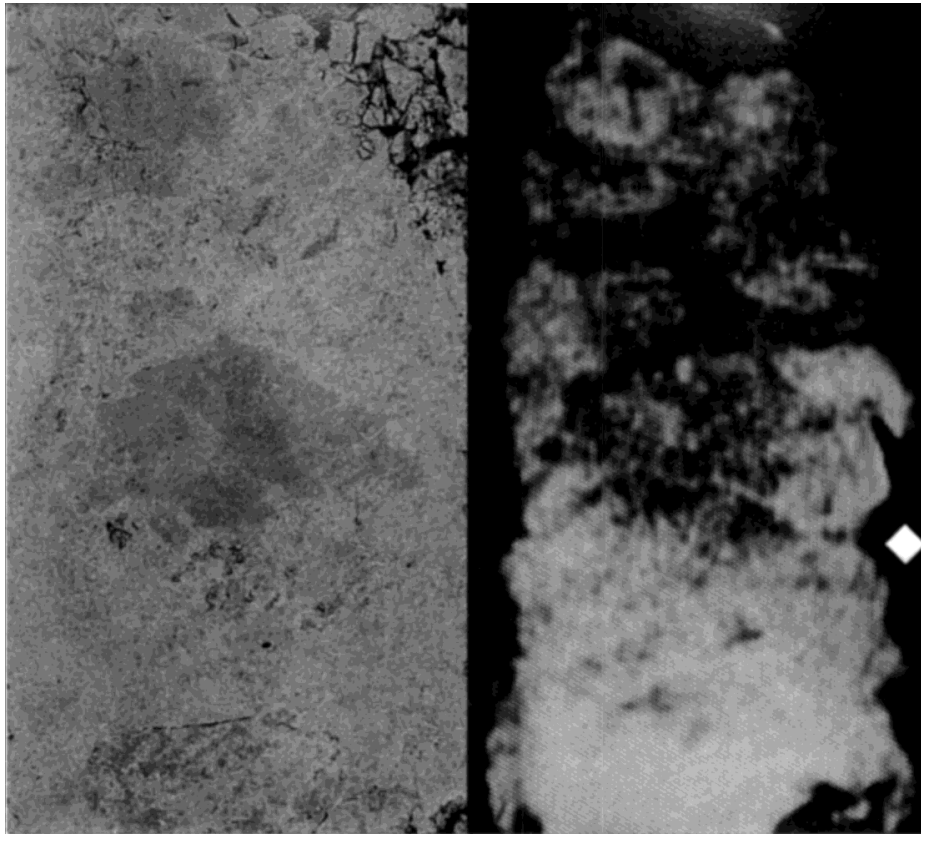

Figure 2 (continued). tionship, density and porosity estimated by CT scan and resistivity are generally in good agreement with the laboratory measurements of physical properties by the mass/volume method. The CT method, therefore, can play a role in determining high-resolution densities that cannot be acquired by conventional methods such as GRAPE. In addition, sample disturbances can also be easily detected by CT scan images. Characteristic convolutional textures in CT images perpendicular to core axes are good indicators of drilling disturbance. Thus, the CT method will be indispensable for obtaining reliable density data at high resolution and for observing internal structures, although it is expensive tool.

\section{ACKNOWLEDGMENTS}

I acknowledge the assistance of the SEDCO crew and the ODP technical staff. H. Noro and Y. Inouchi provided helpful comments about digital image processing. I am indebted to $\mathrm{K}$. Okatsu and $\mathrm{T}$. Munakata for help in studies using the CT scanner in JNOC. Critical reviews and comments by T.H.Orsi and an anonymous reviewer are gratefully acknowledged. Thanks are due to Toshiba Medical, Inc., for permission to use the CT scan data format. 

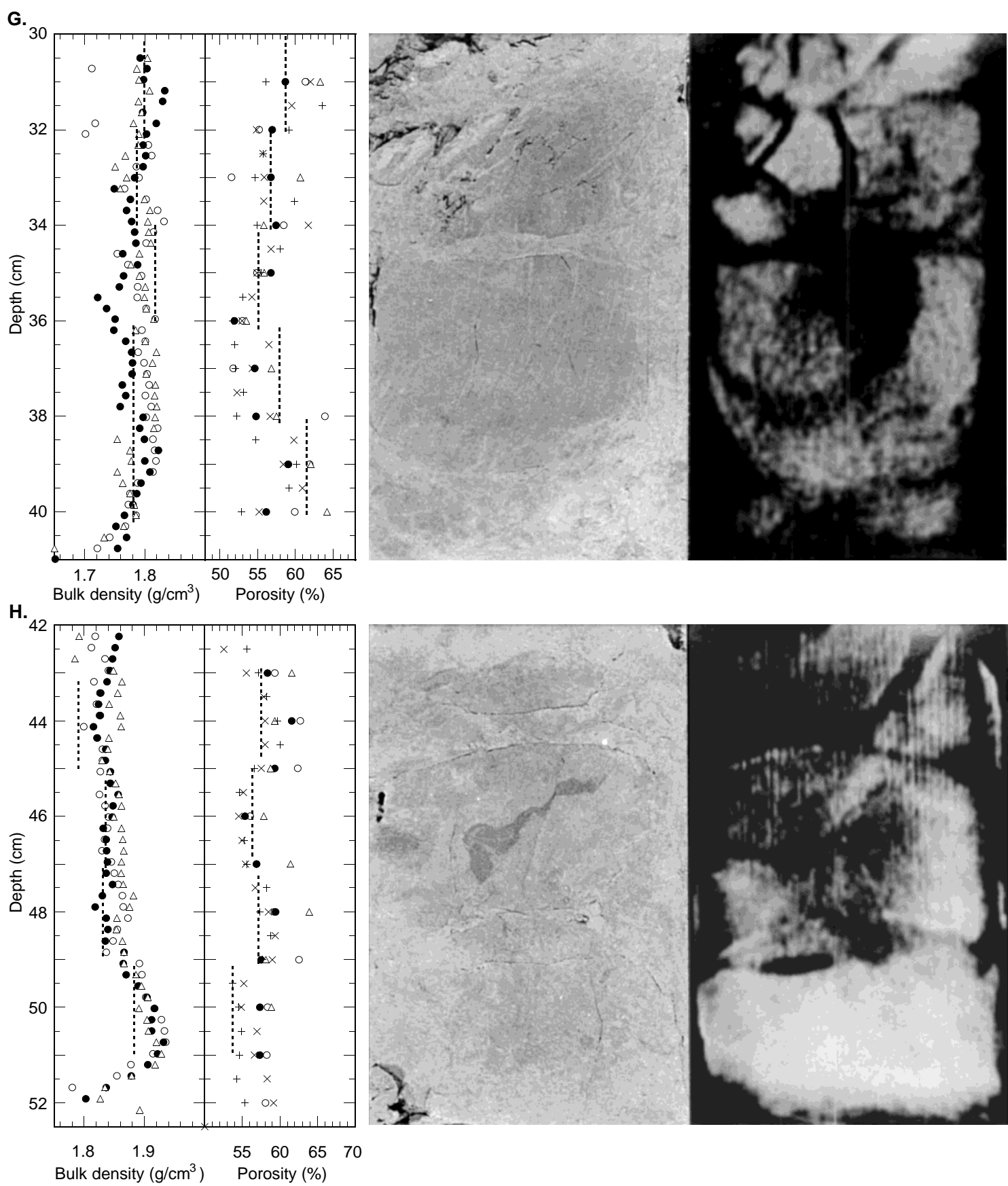

Figure 2 (continued).

\section{REFERENCES}

Archie, G.E., 1942. The electrical resistivity log as an aid in determining some reservoir characteristics. J. Pet. Technol., 5:1-8.

Ashi, J., 1995. CT scan analysis of sediments from Leg 146. In Carson, B.,Westbrook, G.K., Musgrave, R.J., and Suess, E. (Eds.), Proc. ODP, Sci. Results, 146 (Pt. 1): College Station, TX (Ocean Drilling Program), 191-199.

Boespflug, X., Long, B.F.N., and Occhietti, S., 1995. CAT-scan in marine stratigraphy: a quantitative approach. Mar. Geol., 122:281-301.

Boyce, R.E., 1968. Electrical resistivity of modern marine sediments from the Bering Sea. J. Geophys. Res., 73: 4759-4766.

Evans, H.B., 1965. GRAPE - a device for continuous determination of material density and porosity. Trans. SPWLA 6th Ann.Logging Symp., Dallas, 2:B1-B25.
Holler, P., and Kögler, F.-C., 1990. Computed tomography: a nondestructive, high-resolution technique for investigation of sedimentary structures. Mar. Geol., 91:263-266.

Hounsfield, G.N., 1973. Computed transverse axial scanning (tomography), Part 1. Description of system. Bri. J. Radiol., 46:1016-1022.

Inazaki, T., and Nakano, T. 1993. An image processing system of X-ray CT data for the internal structural analysis of geological specimens. Geoinformatics, 4:9-23.

Iwai, Y., 1979. CT Scanner-X-ray Computed Tomography Scanner: Tokyo (Coronasha Publ.). (in Japanese)

Kenter, J.A.M., 1989. Application of computerized tomography in sedimentology. Mar. Geotechnol., 8:201-211.

Kermabon, A., Gehin, C., and Blavier, P., 1969. A deep-sea electrical resistivity probe for measuring porosity and density of unconsolidated sediments. Geophysics, 34:554-571. 
I.
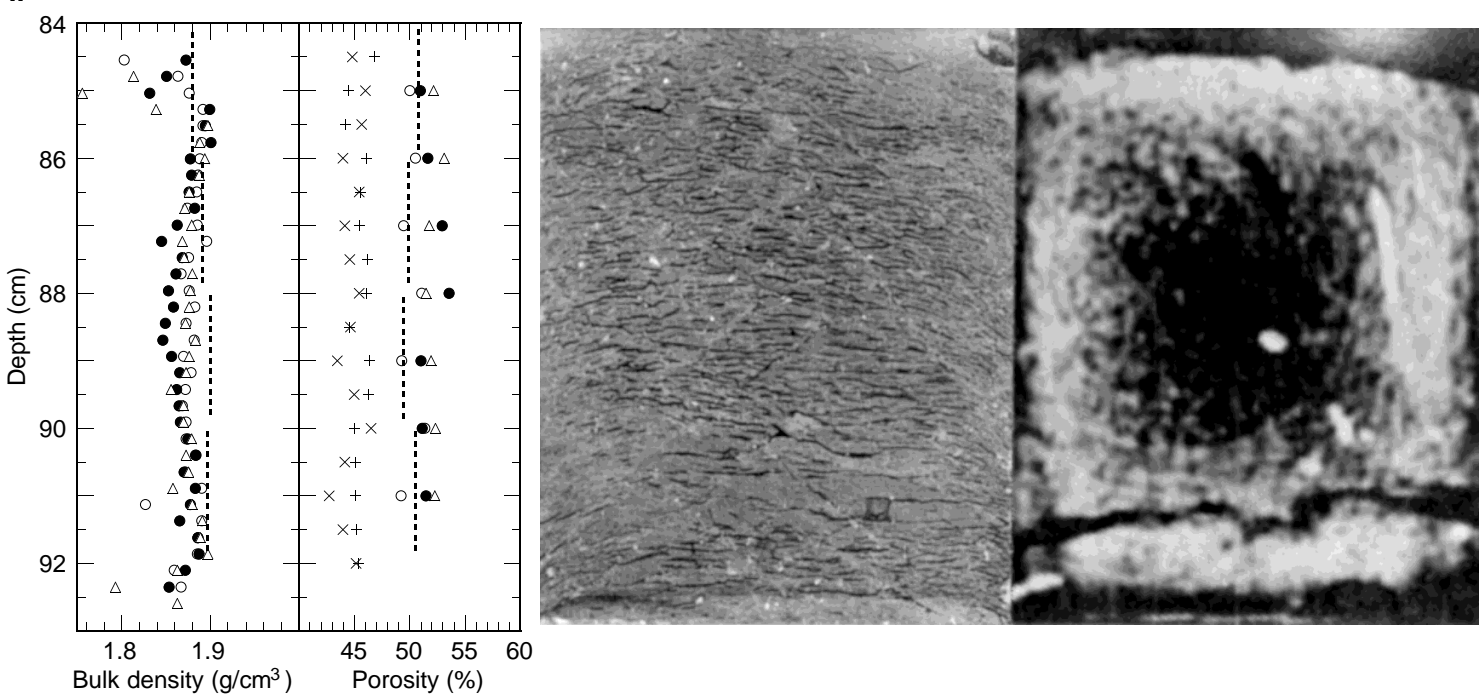

Figure 2 (continued).

Kimura, G., Koga, K., and Fujioka, K., 1989. Deformed soft sediments at the junction between the Mariana and Yap Trenches. J. Struct. Geol., 11:463-472.

Lovell, M.A., 1985. Thermal conductivity and permeability assessment by electrical resistivity measurements in marine sediments. Mar. Geotechnol., 6:205-240.

Moore, J.C., Shipley, T.H., Goldberg, D., Ogawa, Y., Filice, A., Fisher, A., Jurado, M.-J., Moore, G.F., Rabaute, A., Yin, H., Zwart, G., Brückmann, W., Henry, P., Ashi, J., Blum, P., Meyer, A., Housen, B., Kastner, M., Labaume, P., Laier, T., Leitch, E.C., Maltman, A.J., Peacock, S., Steiger, T.H., Tobin, H.J., Underwood, M.B., Xu, Y. and Zheng, Y., 1995. Abnormal fluid pressures and fault-zone dilation in the Barbados accretionary prism: Evidence from logging while drilling. Geology, 23:605-608.

Morgan, C.L., 1983. Basic Principles of Computed Tomography: Baltimore, MD (University Park).

Orsi, T.H., 1994. Computed Tomography of Macrostructure and Physical Property Variability of Seafloor Sediments. Ph.D. Thesis, Texas A\&M University, College Station, TX.

Orsi, T.H., Edwards, C.M. and Anderson, A.L., 1994. X-ray computed tomography: A nondestructive method for quantitative analysis of sediment cores. J. Sed. Res., A64:690-693.

Rutledge, A.K., Roberts, J.A., Orsi, T.H., Bryant, W.R. and Kotilainen, A.T. 1995. Geotechnical properties and consolidation characteristics of North
Pacific sediments, Sites 881,883 , and 885/886. In Rea, D.K., Basov, I.A., Scholl, D.W., and Allan, J.F. (Eds.), Proc. ODP, Sci. Results, 145: College Station, TX (Ocean Drilling Program), 525-546.

Shipley, T.H., Ogawa, Y., Blum, P., et al., 1995. Proc. ODP, Init. Repts., 156: College Station, TX (Ocean Drilling Program).

Soh, W., Byrne, T., Taira, A., and Kono, A., 1993. Computed tomography (CT) scan image analysis of Site 808 cores: structural and physical property implications. In Hill, I.A., Taira, A., Firth, J.V., et al., Proc. ODP, Sci. Results, 131: College Station, TX (Ocean Drilling Program), 135140.

Tamaki, K., Piscicotto, K., Allan, J., et al., 1990. Proc. ODP, Init. Repts., 127: College Station, TX (Ocean Drilling Program).

Vinegar, H.J., 1986. X-ray CT and NRM imaging of rocks. J. Pet. Technol., $3: 257-259$.

Westbrook, G.K., Carson, B., Musgrave, R.J., et al., 1994. Proc. ODP, Init. Repts., 146 (Pt. 1): College Station, TX (Ocean Drilling Program).

Date of initial receipt: 5 February 1996

Date of acceptance: 30 August 1996

Ms 156SR-019 


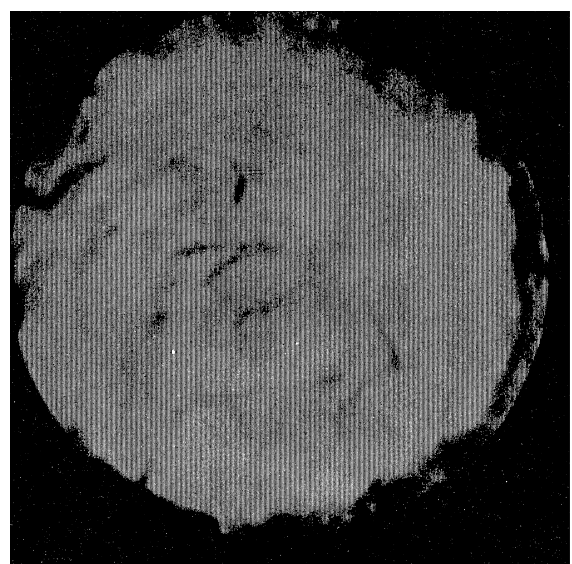

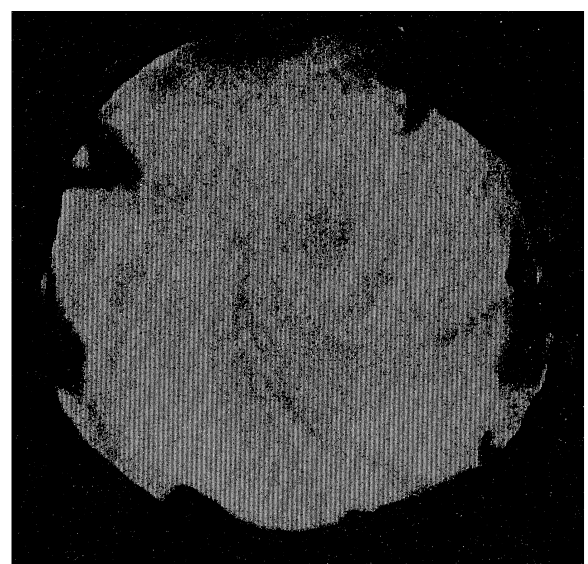

$\mathbf{D}$

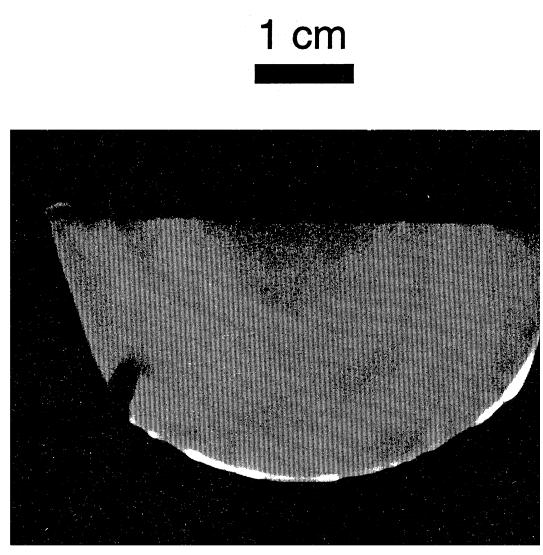

ก

Figure 3. Examples of CT scan images showing drilling disturbance obtained using the Xforce-type scanner. Images are perpendicular to the core axes. A. Sample 948-8. B. Sample 949-14. C. Sample 948-15. The positions of slice images are shown in Figure 2 (diamonds).

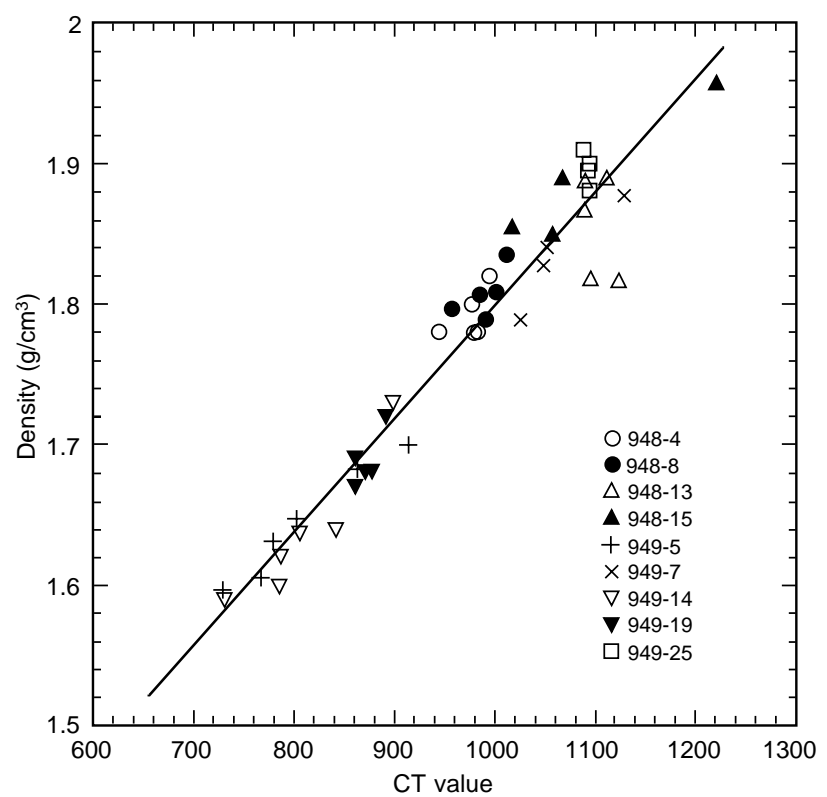

Figure 4. Scatter plot of CT values vs. mass/volume derived densities with the best-fit line derived from standard sample measurements. Note the relatively large deviation from the best-fit line in Samples 948-8 (solid circle), and 948-13 (triangle). See text for explanation. 